\title{
ATTITUDES AND PERSONAL POSITION OF INITIAL TEACHERS FOR IMPLEMENTATION OF ENTITY-SUBJECTIVE RELATIONS IN TECHNOLOGICAL EDUCATION
}

\author{
G. Bistreva* \\ Faculty of Education, Trakia University, Stara Zagora, Bulgaria
}

\begin{abstract}
The aim of the study was to identify the attitudes of primary school teachers for the implementation of subject-subjective relations in technological training, as well as their personal position on this issue. The survey is conducted using a survey of primary school teachers from various primary schools in different types of settlements.

For this purpose, using questionnaires.

Participation in the survey taken $\mathbf{8 0}$ primary teachers.

Based on the results obtained and the summary can be concluded that primary teachers have the necessary technological competence. In learning content are no alternatives for the realization of subject-subjective relations, is of the teacher is not required to perform such regulated relations. This is a reason to treat the technological competence of primary teachers in the field of traditional and basic understanding of it-work on instruction and model; the formation of technological culture among students and a positive attitude to work. Still felt the need to understand that through technological education in primary school can be taught, oriented not only to society but also to develop the qualities of the individual. At present educational content in home life and technique provides alternatives to the teacher to have support for the realization of subject-subjective relationship with each student - it is universal. This requires teachers to reconstruct the content of individual technological tasks.
\end{abstract}

Key words: students, primary teachers, subject-subjective relations, technological education, primary school.

\section{INTRODUCCTION}

In modern pedagogical practice in creasingly strong view of realization of pedagogical interaction with pupils (implementing subjectsubjective relations), not only in technological training, and all subjects in elementary school. The idea of subject-subjective relations is not new. It is a form of personal oriented approach in training. At its stand understanding that to be the student body must respect his personality, his individual cognitive and practical possibilities before him there must be opportunities for independent choice of activity.

In the specialized pedagogical literature there are numerous definitions of view subjectsubjective relations. But the question "How initial teacher to make similar arrangements in their teaching practice?", The literature does not answer. That is the main reason for

\footnotetext{
${ }^{*}$ Correspondence to: Gabriela Bistreva, Faculty of Education, Trakia University - Stara

Zagora,Bulgaria,gabriela_bistreva@abv.bg
}

carrying out the survey, which reflects the level of knowledge in science and the state of pedagogical interaction in technological education in primary school.

\section{METHODOLOGY OF THE RESEARSH}

The study was conducted using a survey of primary school teachers from various primary schools in different types of settlements. Primary school teachers meet the different types of questions related to the implementation of subject-subjective relations in technological education in primary school.

The object are subject-subjective relations in technological training I - IV class.

The study focuses on attitudes and personal position of primary school teachers for the implementation of object-subjective relations in technological education in primary school.

The aim of the study was to determine the attitude of primary school teachers for the implementation of object-subjective relations 
in technological training, as well as their personal position on this issue

\section{CRITERIA OF ANALYZING THE REZULTATS}

The survey results are analyzed by the following criteria:

$\checkmark$ Awareness of developments in pedagogical theory;

$\checkmark$ Sensitivity to new pedagogical ideas and solutions;

$\checkmark$ Personal position on the issue of implementation of subject-subjective relations training;

$\checkmark$ Professional competence of technological education.

\section{RESULTS}

With respect to the first criterion "Awareness of teachers on the developments in pedagogical theory" $39 \%$ of primary school teachers believe that the view of not carrying out an educational impact and pedagogical interaction in modern conditions apply. 58\% share the view that the implementation of subjectsubjective relations is more applicable, $3 \%$ rather not applicable. There are no definitive answers, that this view is not applicable.

The results obtained in the first criterion can be concluded that satisfactorily surveyed primary school teachers were informed about developments in their field. As evidence for this is the high number of participations in training courses this year. A study further establishes the extent awareness of primary teachers on the developments in pedagogical theory is transformed into real, everyday pedagogical practice.

Important for us are the results of a second criterion "Sensitivity to new pedagogical ideas and solutions." They show the attitudes and awareness of primary teachers to new approaches in technology training; what is readiness for their application; account you need to change traditional views of education.

Respondents primary teachers is a question whether if any topic of textbook Home and equipment include such content, to enable the student to choose and carry out activities corresponding to its capabilities and supporting his joy, the student will be subject in training. Almost half of respondents (45\%) responded that if such content ensure the student will be subject; $50 \%$ responded that the student will be more in the position of the subject, and 5\% soon will be. These results are evidence of the difficulties encountered by teachers. These difficulties are connected on one side to the non-use of modern, person-centered approaches to learning that suggest consideration of differences of children. On the other hand the difficulties arising from the uniform educational content in home life and technique - covering such topics that all students made the same article. Through the presence of a differentiated educational content in Home and technique teacher would be considerably facilitated in the performance of subject-subjective relations in technological training.

As regards the second criterion can be concluded that some of the teachers have a high sensitivity to new pedagogical ideas and solutions. They recognize the need for new approaches. The majority of primary school teachers recognize the need for new solutions, but have seen a lower sensitivity, volatility and uncertainty in terms of opportunities for placing students in the position of a subject through the choice of activity.

As regards the third criterion "Personal position of the teacher to the problem of realization of subject-subjective relations in education" $45 \%$ of respondents primary school teachers are of the opinion that it is necessary to carry out subject-subjective relations training. The remaining $45 \%$ of teachers believe that more is needed to carry out those relationships. Only 5\% of respondents are of the opinion that the subject-subjective relations in the education and upbringing of the students of primary school age do not need to be implemented. A high percentage - $64 \%$ of primary teachers surveyed believe that it is necessary to consider the individual characteristics of students in the implementation of pedagogical interaction with him (subject-subjective relations). Thirty-two percent of primary school teachers $(32 \%)$ believe that more needs to be reported individually-psychological characteristics of students. We assume that the results are such as initial teacher from one country to comply with state educational standards that students must meet, and on the other respecting the individual psychological - their characteristics. As a result, initial teacher training approaches used by which seeks to achieve an average level in the class / classes to enable all students to meet the state standard. Four percent of those surveyed teachers (4\%) reported that more is not necessary to consider the individual characteristics of each student in the daily training.

Whether there are objects in the primary school, in training the student is subject, $50 \%$ of respondents primary school teachers are of the opinion that no such items. The percentage 
of these teachers is quite high. We assume that this is because much of the attention of teachers is directed to: establish rules and discipline in the class / classes (period of adaptation of first-graders); striving to equalize the level of knowledge of students to cover the state standard; management of educational content binding. The rest $(50 \%)$ of respondents consider that there are objects in teaching the student may be in the position of the subject. Listed items are: Music, ISF, Arts, Home and equipment, Mathematics, Bulgarian language and English. Although only half of the respondents are adamant position of the student body, but not in all subjects, though this fact is encouraging.

With regard to the fourth criterion "Professional competence of technological training" Fifty-five percent (55\%) of them responded that comply with opportunities to achieve individual success and experience the feeling of satisfaction each student. Thirty-two percent $(32 \%)$ of respondents say they comply with planned activities with the theme of the book and the difficulty of the planned technological operations. This fact supports the assumption that the work of instruction and model and provided themes of educational content is a priority of the majority of teachers. Only 23\% of primary school teachers account individual abilities of each student in developing the product.

It is known that the educational content of each course is support for teachers. Support for primary teachers is the educational content of the Home and equipment, although at present it is not differentiated. Despite reporting this fact, $9 \%$ of respondents primary school teachers are of the opinion that the current educational content in Home and equipment provided to each student activity, consistent with its individual cognitive and practical possibilities. Forty-one percent $(41 \%)$ of them responded that more educational content provides such activity, and 32\% - rather not. Small proportion of primary school teachers (9\%) reported that the educational content in Home and technique is not differentiated and provides activities to suit individual cognitive and practical possibilities of each student. Nine percent of the respondents (9\%) can not decide whether through educational content allows for this kind of activity.

\section{CONCLUSION}

As regards the fourth criterion can be made the following summary: most of primary school teachers are of the opinion that the student may be subject in teaching Home and equipment. This position, however, the student is determined not only by the requirements provided (work instructions and template). To carry out subject-subjective relations is necessary for every student to enable activity and creativity, to report his individual psychological and cognitive capabilities, to respect his personality. On the one hand the student is placed in such a position by the teacher, and the other - the educational content is a prerequisite and support teacher to do so.

Based on the results obtained and the summary can be concluded that primary teachers have the necessary technological competence. In learning content are no alternatives for the realization of subject-subjective relations, it of the teacher is not required to perform such regulated relations. This is a reason to treat the technological competence of primary teachers in the field of traditional and basic understanding of it - work on instruction and model; the formation of technological culture among students and a positive attitude to work. Still felt the need to understand that through technological education in primary school can be taught, oriented not only to society but also to develop the qualities of the individual. At present educational content in home life and technique provides alternatives to the teacher to have support for the realization of subjectsubjective relationship with each student - it is universal. This requires teachers to reconstruct the content of individual technological tasks.

\section{REFERENCES}

1. Vasilev, D. (1992) Pedagogy. University edition. Sofia

2. Ivanov, G. (2008) Pedagogical interaction in technological preparation of children from 3 to 11 years. Stara Zagora

3. Ivanov, G. (2008) Employment skills of small pupil. Stara Zagora.

4. Ivanov, G. (2008) Multi-sensing in technical and technological training. Stara Zagora. 